\title{
INFLUENCE OF THE MODEL SIZE IN THE NUMERICAL DETERMINATION OF THE AVERAGE THERMAL STRESSES IN AN MMC COMPOSITE
}

\author{
C. A. de J. Miranda ${ }^{a}$, \\ R. M. P. Libardi ${ }^{\text {, }}$ \\ S. Marcelino ${ }^{c}$, \\ and Z. M. de Boari ${ }^{\mathrm{d}}$ \\ ${ }_{\text {a,b,c }}$ Instituto de Pesquisas Energéticas e \\ Nucleares \\ IPEN-CNEN/SP \\ Cidade Universitária \\ CEP 05508-000, São Paulo, SP, Brasil \\ ${ }^{\mathrm{d}}$ Fundação Nacional de Desenvolvimento das \\ Escolas Superiores Particulare \\ SCSQ. 07BI. "A" Sala 726/728 - Torre do \\ Pátio Brasil - CEP 07307 - 901, Brasilia/DF

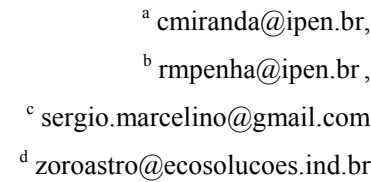 \\ a cmiranda@ipen.br, \\ brmpenha@ipen.br \\ d zoroastro@ecosolucoes.ind.br
}

\section{ABSTRACT}

In previous works the authors discussed some issues related to a specific metallic matrix composites (MMC), the Aluminum matrix reinforced with $\mathrm{SiC}$ particles $(\mathrm{Al}+\mathrm{SiC})$ which has a metal matrix (powder) mixed with ceramic particles. These materials have some advantages when used as a structural material such as their high strength and good conformability. Their properties depend, among others, on the volumetric ratio, the particles size and distribution besides the matrix microstructure itself. Some of them are obtained at elevated temperature what produces a thermal stress state in the material. The $\mathrm{Al}+\mathrm{SiC}$ is one of the later. The powder mix is extruded at $600{ }^{\circ} \mathrm{C}$ and it is used at $20{ }^{\circ} \mathrm{C}$. Several numerical analyses were performed considering the random distribution of the particles and a non-linear behavior in the aluminum matrix. The results showed strong influence of the aluminum elastic-plastic behavior in the composite thermal stress distribution due to its manufacturing process. However, one issue remained: the size of the model. It represents the central portion of a $\mathrm{Al}+\mathrm{SiC}$ bar which is only about 10 times the size of a single particle $(\sim 10 \mathrm{~L})$. The present work investigates, always numerically, the influence of the model size on the thermal stress distribution. It considers 2 sets of non-linear analyses with random distributed particles: one with 20 models with size of $20 \mathrm{~L}$ each one, the other set with another 20 models with size $40 \mathrm{~L}$. This approach allows a view of the results tendency compared with the $10 \mathrm{~L}$ ones. As done before, the modeled volumetric ratio has a very tight range of values with its average very near to the value in an actual $\mathrm{Al}+\mathrm{SiC}$ composite. It is showed that the first model size was already enough to get good results without sacrificing neither the computer nor the analyst time.

Keywords: composite; metallic matrix particles; thermal stresses

$\sigma \quad$ stress, $\mathrm{MPa}$
Subscripts
a, $\mathrm{M}$ aluminum matrix
s, I SiC particle
p most probable stress

\section{INTRODUCTION}

Metal Matrix Composites (MMC) have several advantages when compared to 'pure' materials that make them very important in several structural applications. This composite can be molded and treated as any other metal alloy. When compared to polymers, the MMC presents high electrical and thermal conductivity and, yet, high mechanical strength.

The mechanical properties of MMC depend on the volumetric ratio, shape, size, and distribution of the disperse phase, and also depend on the matrix microstructure. There are composites formed by particles (big or small) and others formed by fibers (long or short) that interact in different ways, as described in the literature, e.g., Nardone and Prewo (1985), Humphreys, Basu and Djazeb (1991). 
The fiber strength theory, considering the particles volumetric ratio, geometry and mechanical properties as well as the matrix characteristics, explains the mechanical properties of the composites reinforced with long fibers (Kelly and Mcmillan, 1986). The composite material reinforced with particles lacks of a well established formulation, and additionally, the microstructure itself, poses a great deal of complexity to the problem, modifying its properties and strength.

When the matrix of the MMC is Aluminum and the disperse phase are Silicon Carbide particles $(\mathrm{SiC})$, herein referred as $\mathrm{Al}+\mathrm{SiC}$, the composite material is obtained by the mixture of the two materials, reduced to fine particles as in a powder, heated at high temperatures, usually about $600^{\circ} \mathrm{C}$. This heated mixture is extruded to form bars with the dimensions that fits their final usage, usually at room temperature $\left(20^{\circ} \mathrm{C}\right)$, after the cool down process.

Therefore, besides the mechanical stress that acts on the material upon the specific application that it is intend for, there is an additional state of thermal stress due to the thermal gradient $\left(-580^{\circ} \mathrm{C}\right)$. This thermal stress state is due to the distinct thermal expansion coefficients of its components, Aluminum and $\mathrm{SiC}$, during the cooling process, and also their distinct elasticity modules.

The increase of the MMC mechanical strength relies (a) on the restraint that the particles impose to the discordance movement through the material and (b) on the discordance density around the particles.

Typically, particles have dimensions about $\sim 1$ $\mu \mathrm{m}$ and act in the sense of restraining the matrix movement in their whereabouts absorbing, in this way, part of the load. The matrix carries most of the applied load while the particles oppose to the movement of discordances.

The evaluation of the thermal stress in the MMC was the subject of a previous work, as will be seen in detail next. Two cases were analyzed: first considering the material linear behavior (both, analytical and numerical analysis were performed), secondly considering the material non-linear behavior (only numerical analysis). In both cases, the influence of the volumetric ratio, besides size and shape of the particles of $\mathrm{SiC}$, were considered.

The results showed the strong influence of the aluminum matrix elastic-plastic behavior on the composite thermal stress distribution due to its manufacturing process and a minor influence of the volumetric ratio. However, one issue remained: the size of the models. Each one represents the central portion of an $\mathrm{Al}+\mathrm{SiC}$ bar and it is only about 10 times the size of a single particle $(\sim 10 \mathrm{~L})$.

The present work investigates, always numerically, the influence of the model size on the thermal stress distribution. It considers 2 sets of nonlinear analyses with random distributed particles of a generic quadrilateral shape and random size: (a) one set with 20 models (size 20L each) and (b) the other set also with another 20 models but with size 40L. This was done to allow a view of the results tendency compared with the previous ones. Again, the modeled volumetric ratio has a very tight range of values with its average very near to the value in an actual $\mathrm{Al}+\mathrm{SiC}$ composite.

\section{PREVIOUS WORK}

The complex interaction between the particles and the metallic matrix poses a big difficulty to develop an analytical model that allows predicting the thermal stress level in this composite material. Even more if we consider that locally, at the interface between the particles and the metallic matrix, high levels of stress will arise. Despite this difficulty and assuming linear behavior for the materials, Boari (2003) developed an analytical model to predict the most probable average thermal stress within a composite material of $\mathrm{Al}+\mathrm{SiC}$, considering the influence of the volumetric ratio of its disperse phase (the $\mathrm{SiC}$ particles).

\section{Analytical Formulation (Linear)}

In his analytical approach to predict the most probable thermal stress in an MMC composite due to the fabrication process, Boari (2003) assumes a linear elastic behavior of the material (mainly Aluminum) as basic hypothesis. That work was verified against numerical analyses.

The approach to predict the most probable thermal stress in an MMC composite was an adaptation of the Maxwell-Boltzmann statistics (Beiser, 1963) and the Eshelby's method, based on the internal stress equilibrium (see, for instance, Clyne \& Withers, 1993 and Withers \& Pedersen, 1989). The main scope of the distribution law is to study how the particles, which form a system, are distributed in their phase space. When one found the probabilities of all possible distributions in the system nature, it is possible to obtain that particular most probable distribution.

The Maxwell-Boltzmann distribution law has two terms: one associated with particle distribution and other associated with kinetic energy. In the Boari's model (2003) the second term was replaced by the elastic potential energy, in this case, the elastic stress. With this change it is possible to search for the most probable combination of particle position and elastic stress in the material.

Details of the analytical formulation developed to obtain the most probable thermal stress in this kind of composite material, as well as more details of his numerical analyses can be found in the references, for instance in Boari (2003). The summarized formulation shown below was presented previously elsewhere. 


$$
\begin{array}{r}
n(\sigma)=4 \pi N\left(\frac{3}{2 C_{M} K \pi}\right)^{3 / 2} \sigma^{2} e^{-\frac{3 \sigma^{2}}{K 2 C_{M}}} \\
K=f C_{M}\left\{(S-I)\left\{\left(\mathrm{C}_{\mathrm{M}}-\mathrm{C}_{\mathrm{I}}\right)[\mathrm{S}-\mathrm{f}(\mathrm{S}-\mathrm{I})]-\mathrm{C}_{\mathrm{M}}\right\}^{-1}\right. \\
\left.\mathrm{C}_{\mathrm{I}}\left(\alpha_{I}-\alpha_{M}\right) \Delta T\right\}^{2}
\end{array}
$$

Equation (1) represents the stress distribution $n(\sigma)$ in the composite for a random distribution of $\mathrm{N}$ particles with a nominal volumetric ratio $f$. The factor $K$ is given in Eq. (2).

In these equations, $\mathrm{S}$ is the Eshelby's tensor, I is the identity matrix, $\alpha_{M}$ and $\alpha_{I}$ are thermal expansion coefficients tensor's, respectively for the matrix and particles, and $\Delta \mathrm{T}$ is the temperature range experienced by the material.

The elastic tensors components of the Aluminum matrix $\left(\mathrm{C}_{\mathrm{M}}\right)$ and $\mathrm{SiC}$ particles $\left(\mathrm{C}_{\mathrm{I}}\right)$ are given explicitly by the set of equations below, where $\mathrm{E}_{\mathrm{M}}$ and $\mathrm{E}_{\mathrm{I}}$ are the matrix and particles elastic modulus and $v_{\mathrm{M}}$ and $v_{\mathrm{I}}$ are the matrix and particles Poisson's ratio.

$$
\begin{array}{r}
\mathrm{C}_{\mathrm{Mii}}=\mathrm{E}_{\mathrm{M}}\left(1-v_{\mathrm{M}}\right) /\left(1-2 v_{\mathrm{M}}\right)\left(1+v_{\mathrm{M}}\right) \\
\mathrm{C}_{\mathrm{Mij}}=\mathrm{E}_{\mathrm{M}} v_{\mathrm{M}} /\left(1-2 v_{\mathrm{M}}\right)\left(1+v_{\mathrm{M}}\right) \\
\mathrm{C}_{\mathrm{M} 44}=\mathrm{E}_{\mathrm{M}} / 2\left(1+v_{\mathrm{M}}\right) \\
\mathrm{C}_{\mathrm{Iii}}=\mathrm{E}_{\mathrm{I}}\left(1-v_{\mathrm{I}}\right) /\left(1-2 v_{\mathrm{I}}\right)\left(1+v_{\mathrm{I}}\right) \\
\mathrm{C}_{\mathrm{Iij}}=\mathrm{E}_{\mathrm{I}} v_{\mathrm{I}} /\left(1-2 v_{\mathrm{I}}\right)\left(1+v_{\mathrm{I}}\right) \\
\mathrm{C}_{\mathrm{I} 44}=\mathrm{E}_{\mathrm{I}} / 2\left(1+v_{\mathrm{I}}\right) \\
\mathrm{C}_{\mathrm{Iij}}=\mathrm{E}_{\mathrm{I}} v_{\mathrm{I}} /\left(1-2 v_{\mathrm{I}}\right)\left(1+v_{\mathrm{I}}\right) \\
\sigma_{p}^{2}=\frac{2 f C_{M}^{2}\left\{(\mathrm{~S}-I)\left\{\left(\mathrm{C}_{\mathrm{M}}-\mathrm{C}_{\mathrm{I}}\right)[\mathrm{S}-\mathrm{f}(\mathrm{S}-\mathrm{I})]-\mathrm{C}_{\mathrm{M}}\right\}^{-1} \mathrm{C}_{\mathrm{I}}\right.}{3} \\
\frac{\left.\left(\alpha_{\mathrm{I}}-\alpha_{\mathrm{M}}\right) \Delta T\right\}^{2}}{3}
\end{array}
$$

The most probable stress in the material, $\sigma_{P}$, is associated with the maximum Eq. (1) and is given by Eq. (4).

To validate his analytical results, Boari (2003) developed a set of numerical analyses (simulations using Finite Elements) in which the particles (of circular geometry, to be coherent with the underlined theoretical hypothesis) were generated in random positions and sizes. The materials (Aluminum and $\mathrm{SiC}$ ) were considered to be linear, in agreement with the theoretical principles used in the analytical part of his work.

The statistical treatment of the set of results obtained by random distributions, allowed estimating the most probable average value of thermal stress in the composite material. This value was considered to be very close to the value that came out from the analytical model, confirming the Boari's analytical approach.

\section{Non-Linear Numerical Analyses}

As the analyses have shown, in some points of the structure the stress values were found to exceed the Aluminum yield strength. Both the analytical and the numerical results had a strong limitation in practical usages, once the Aluminum elastic-plastic behavior would significantly alter the level of average thermal stress in the material.

For this reason, and adopting a reverse procedure, assuming that the analytical results give support to the numerical \& statistical procedure established previously, new studies took place, based only on numerical analysis plus statistical treatment. In these studies, the influence of the particles geometry, circular versus quadrilateral, and material behavior, linear versus non-linear (stress-strain curve for the Aluminum), was systematically examined (Miranda, Libardi, Boari, 2009a, 2009b).

\section{Adopted Material Properties}

For the Aluminum matrix the adopted properties were: Elasticity modulus, $E_{a}=73 \mathrm{GPa}$, specific mass, $\gamma_{\mathrm{a}}=2800 \mathrm{Kg} / \mathrm{m}^{3}$, thermal dilatation coefficient, $\alpha_{\mathrm{a}}=$ $23.610^{-6}{ }^{\circ} \mathrm{C}^{-1}$, Poisson's ratio, $v_{\mathrm{a}}=0.33$, transversal elastic modulus, $\mathrm{G}_{\mathrm{a}}=27.4 \mathrm{GPa}$.

For the $\mathrm{SiC}$ particles the adopted properties are: Elasticity modulus, $E_{\mathrm{S}}=450 \mathrm{GPa}$, specific mass, $\gamma_{\mathrm{S}}=$ $3200 \mathrm{Kg} / \mathrm{m}^{3}$, thermal dilatation coefficient, $\alpha_{\mathrm{S}}=4.0$ $10^{-6}{ }^{\circ} \mathrm{C}^{-1}$, Poisson's ratio, $v_{\mathrm{s}}=0.17$, transversal elastic modulus, $\mathrm{G}_{\mathrm{S}}=192 \mathrm{GPa}$.

Table 1 shows the values of the stress $\sigma \mathrm{x} \varepsilon$ strain curve adopted for the aluminum matrix in all preceding and in the present analyses.

Table 1. Values of the stress $\sigma \times \varepsilon$ strain curve.

\begin{tabular}{|c|c|c|c|c|c|c|c|c|c|c|}
\hline$\sigma(\mathrm{MPa})$ & 146 & 175 & 195 & 205 & 215 & 220 & 225 & 228 & 229 & 230 \\
\hline$\varepsilon(\%)$ & 0.2 & 0.45 & 0.8 & 1.0 & 1.5 & 2.0 & 3.0 & 4.0 & 6.0 & 8.0 \\
\hline
\end{tabular}

Obs.: adopted in all non-linear analyses.

\section{Previous Results}

The results of the numerical analysis, obtained through finite element method, carried out using the ANSYS (V11.0) software, are presented as iso-stress curves associated to the last load-step of the analysis, when the temperature gradient reaches $\Delta \mathrm{T}=-580^{\circ} \mathrm{C}$. Each of these curves is univocally identified by a different color (RGB - Red, Green, Blue). For each analysis, with a random arrangement of particles, the figure generated at $\Delta \mathrm{T}=-580{ }^{\circ} \mathrm{C}$ is processed by a simple and efficient algorithm (Miranda, Libardi, Boari, 2009a) developed in Matlab (v7.6, 2008). The results, showed as iso-stress curves, obtained from 
the analyses using circular particles and those using quadrilateral particles are presented in Fig. 1 (Miranda, Libardi, Boari, 2009c).

The iso-stress curves can be weighted by the percentage that each of these colors (meaning isostress value) appears, in regard to the others, resulting in an average value for the composite material. On the other hand, as assumed in the previous works and also in this work, the value with the higher frequency (percentage) - the mode stress value - was chosen. The set of mode values is treated statistically, considering normal distribution, resulting in an average value (most probable average thermal stress value) and a standard deviation.

From results of previous work (Miranda, Libardi, Boari, 2009a/b/c), it can be seen, as expected, the strong influence of the Aluminum nonlinear behavior: the composite average stress value decreases from $\sim 500 \mathrm{MPa}$ to $\sim 180 \mathrm{MPa}$. This influence is easy to observe in the Fig. 2a, adapted from (Miranda, Libardi, Boari, 2009a), in which the same arrangements of random round particles are submitted to linear and non-linear analyses.
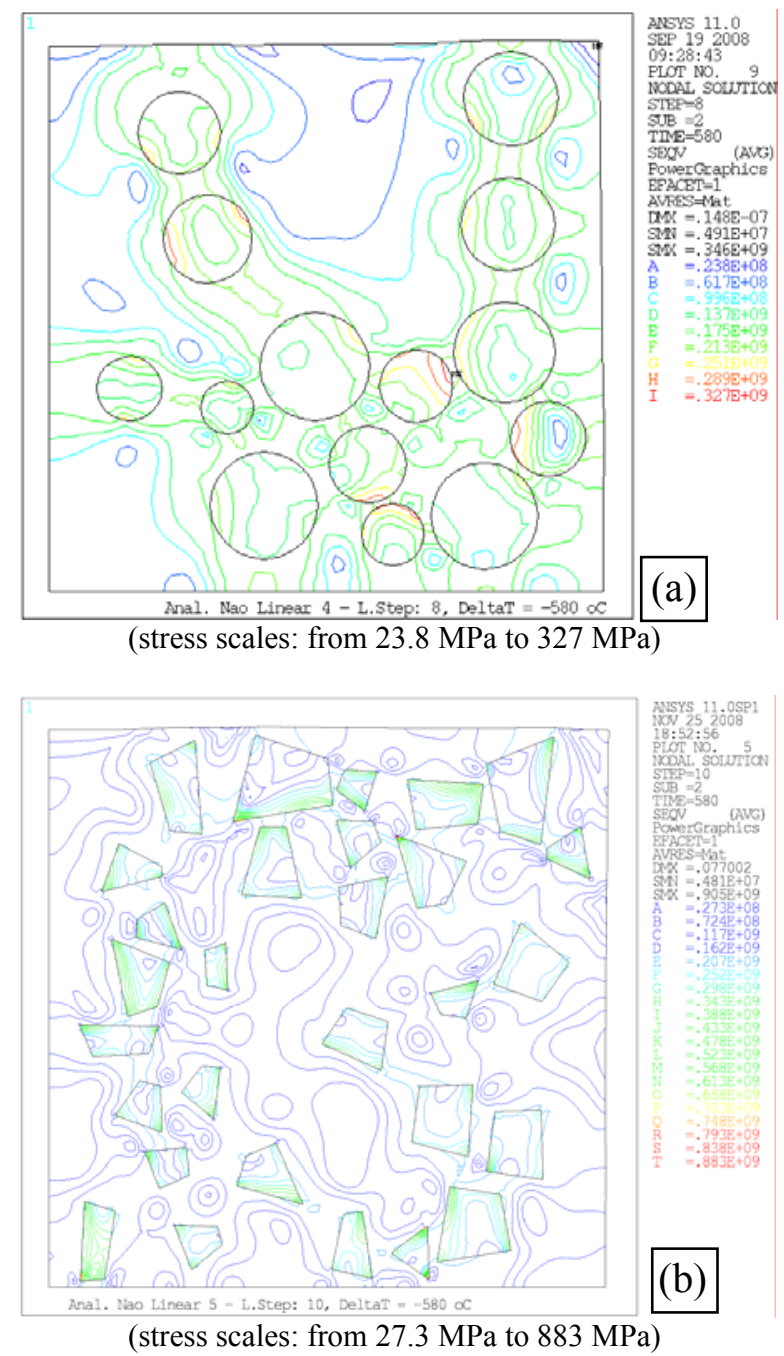

Figure 1. Typical (previous) results at $\Delta \mathrm{T}=-580^{\circ} \mathrm{C}$, (a) Round and (b) Quadrilateral particles.
The results of Boari (2003), assuming the linear behavior of materials, mainly the Aluminum, were compared to the results of the non-linear analyses, where a typical stress-strain curve was used for the Aluminum. Both set of analyses (linear and nonlinear) used the same round particles distribution and the same number of iso-stress curves in the posprocessing stage (9 curves / colors).

When using quadrilateral particles in the nonlinear analyses, the values of maximum stress were found much higher than those of round particles analyses. Due to this fact, when analyzing the stress resulting from the quadrilateral particles distributions, the iso-stresses were firstly generated using 9, 20 and 40 values (colors). The results using 20 or 40 curves gave almost the same values showing a convergence. So, all results were analyzed using 20 iso-stress curves.

Figure 2b, adapted from (Miranda, Libardi, Boari, 2009c), shows the mode and the averaged stress values for all analyses where the values obtained using 09 and 40 iso-stress curves values were suppressed.

From previous results, and considering that the particles of quadrilateral geometry should be more representative than the round geometry, we concluded that the average stress in the $\mathrm{Al}+\mathrm{SiC}$ composite material, fabricated as defined previously, is between $155 \mathrm{MPa}$ e $195 \mathrm{MPa}$ with the confidence interval of $95 \%$, with an average value of $175 \mathrm{MPa}$, and a standard deviation of $10 \mathrm{MPa}$ (Miranda, Libardi, Boari, 2009c).
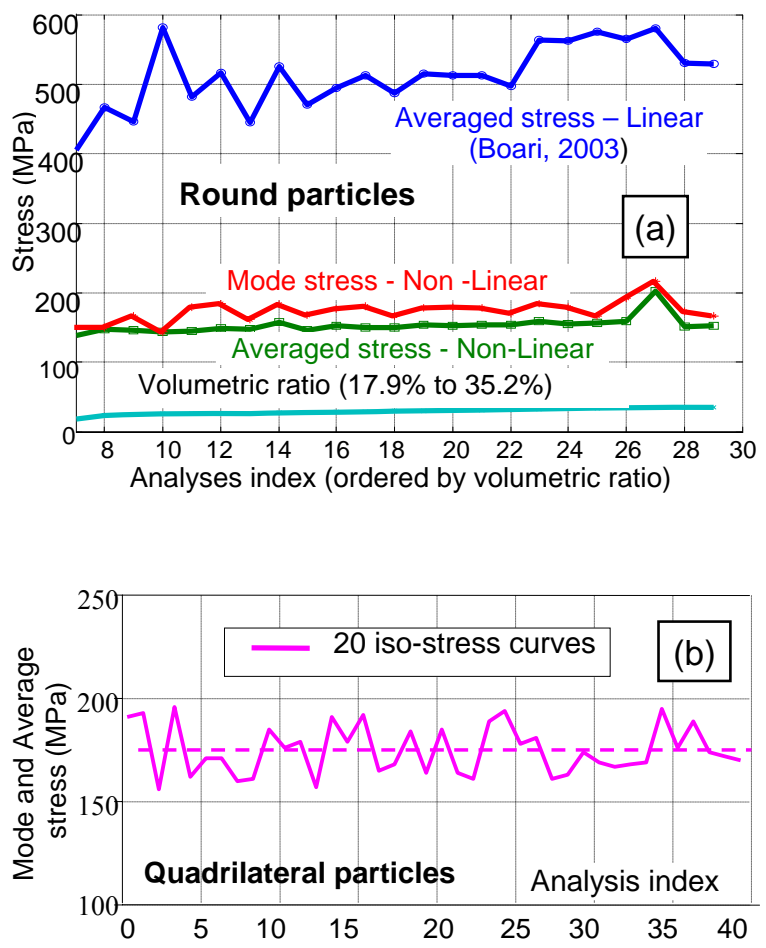

Figure 2. Comparison previous results: (a) NonLinear X Linear numerical results, (b) Mode stress and averaged values. 


\section{PRESENT WORK}

The conclusion presented above, however, doesn't solves one remaining doubt: the appropriate size of the model. As mentioned before, the model used in the previous studies assumes a slice of square cross section geometry, whose side length is about 10 times $(10 \mathrm{~L})$ the particles average size $(\mathrm{L})$.

As the thermal stress depends on the thermal gradient, it is not the absolute value of the particles and models size that matters, but its relative size.

For this reason, the present work analyzed two sets of 20 models each. The size (cross section square's side length) of the first set of models is $20 \mathrm{~L}$ and for the second set it is 40L. In each set it is assumed the quadrilateral geometry to represent the particles whose shape, position and size are random. Typical models/meshes are presented in Fig. 3.
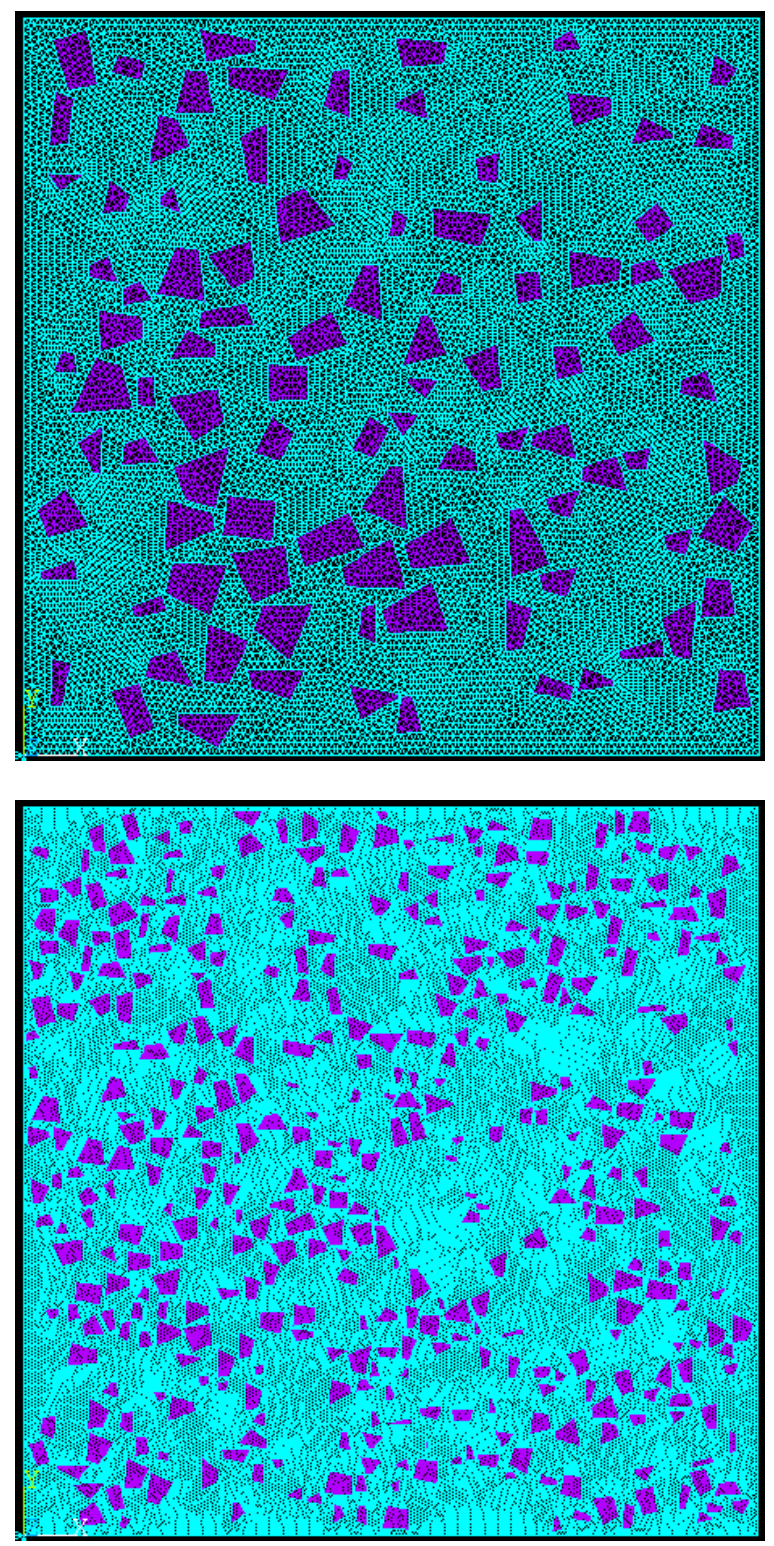

Figure 3. Typical meshes: model 20L \#19 (above), model 40L \#10 (below).
Each model was analyzed using the ANSYS default convergence parameters of a static analysis with non-linear material properties. The results were pos-processed to obtain images with the iso-stress curves at $\Delta \mathrm{T}=-580{ }^{\circ} \mathrm{C}$. These images were analyzed with a Matlab algorithm to identify the percentage of each color (iso-stress value).

\section{Numerical Analyses}

For each model, in both sets, the same properties of the Aluminum and $\mathrm{SiC}$ particles, boundary conditions and thermal loads were specified.

Material properties. The models volumetric ratio has a very tight range of values with its average near the value of an actual $\mathrm{Al}+\mathrm{SiC}$ composite (between 20\% and 23\%). This will allow a direct comparison with the previous results when the volumetric ratio values were between $20 \%$ and $25 \%$. The material properties are the same adopted in the previous analyses (for the Aluminum, see the adopted nonlinear $\sigma \times \varepsilon$ values in Table 1$)$.

Boundary Conditions. The nodes on the $\mathrm{X}$ axis $(\mathrm{Y}=0)$ were restrained in the $\mathrm{Y}$ direction while the nodes on the $\mathrm{Y}$ axis $(\mathrm{X}=0)$ had their $\mathrm{X}$ direction restrained (see Fig. 3 for the axis definition). In this way, the adopted model represents the central portion of a bar and we are assuming that it represents the entire bar cross-section.

Loading. The only applied load is the uniform temperature field imposed in several steps to reach the end of the cooling process, from $600{ }^{\circ} \mathrm{C}$ to $20^{\circ} \mathrm{C}$. So, the last load step is associated with the $\Delta \mathrm{T}=-580$ ${ }^{\circ} \mathrm{C}$. This means it is assumed a controlled slow cooling process to assure an almost uniform temperature over the entire model. The temperature gradient during the cooling process will be present even if the cooling time is long, however its influence is considered negligible once the uniform final temperature state $\left(20^{\circ} \mathrm{C}\right)$ is reached.

\section{Finite Element Results - Models 20L and 40L}

Two typical results from the models $20 \mathrm{~L}$, obtained from the numerical analyses at $\Delta \mathrm{T}=-580$ ${ }^{\circ} \mathrm{C}$, are shown in Fig. 4. In this figure, the iso-stress lines within the composite can be seen with their scale and, also, the particle distribution for that specific model which is one out of twenty.

Figure 5 shows equivalent results from models 40L.

Each one of the 20 iso-stress curves in the last load step, at $\Delta \mathrm{T}=-580^{\circ} \mathrm{C}$, has its own color defined by the $\mathrm{R}(\mathrm{ed}), \mathrm{G}$ (reen) and $\mathrm{B}$ (lue) values used previously in the ANSYS POST1 pos-processor. This color map was used in Matlab program developed to 
analyze the images/figures.

Before the preliminary analyses of the results it should be pointed out the adoption of the Tresca equivalent stress as the parameter to show and compare the results from all analyzes in this work as well as in the previous ones.
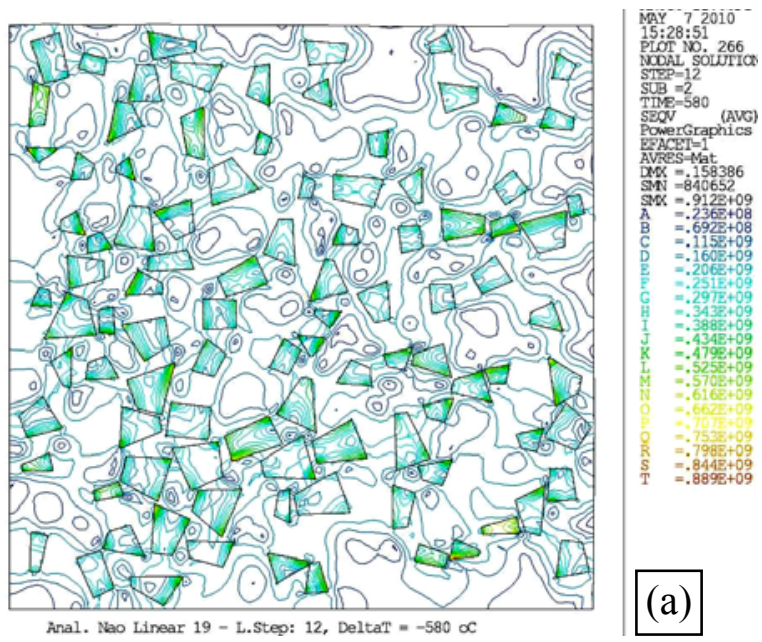

(stress scales: from 23.6 MPa to $889 \mathrm{MPa}$ )
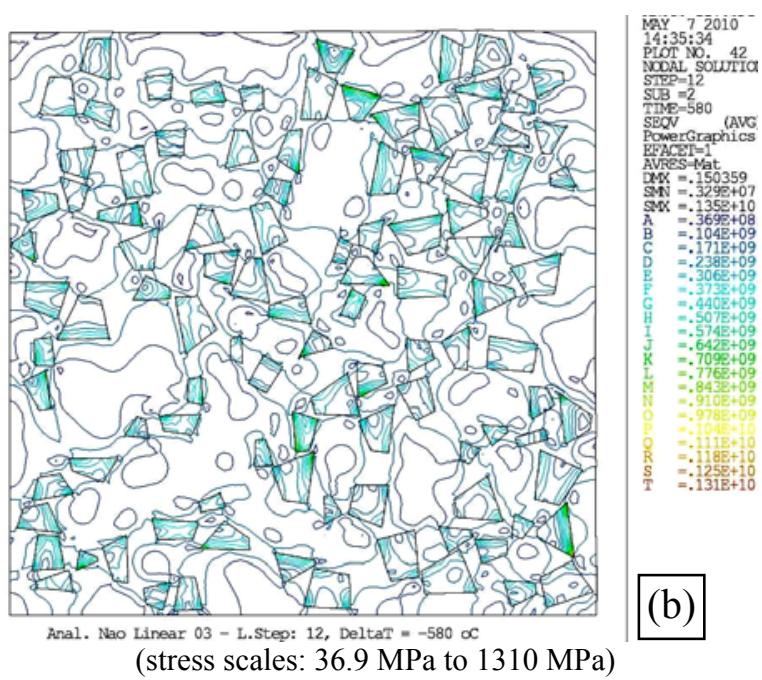

Figure 4. Typical results at $\Delta \mathrm{T}=-580^{\circ} \mathrm{C}$, models $20 \mathrm{~L}$.

Other point to keep in mind: the interest is to obtain the final stress state in the composite, after the end of the cooling process. During the composite cooling there is a temperature transient in which the material properties vary with the temperature.

So, the thermal stresses field will vary nonlinearly. However, the final stress state can be assessed with the procedure described in the item "loading" of this work (it was also adopted in the previous works).

\section{Preliminary Result Analyses}

Figure 6 presents a typical distribution of percentages associated to each iso-stress curve of a typical analysis that is valid to the models ' $20 \mathrm{~L}$ ' as well as to the models ' $40 \mathrm{~L}$ '.

It is clear, from this figure and also from figures 4 and 5, that the percentages associated to the high levels of stress are very low $(\sim 0 \%)$, and can be neglected.
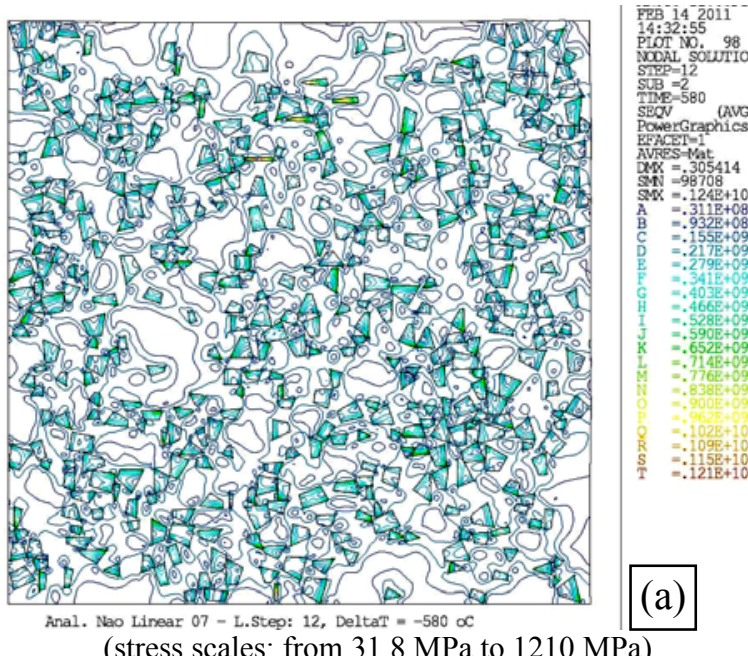

(stress scales: from $31.8 \mathrm{MPa}$ to $1210 \mathrm{MPa}$ )

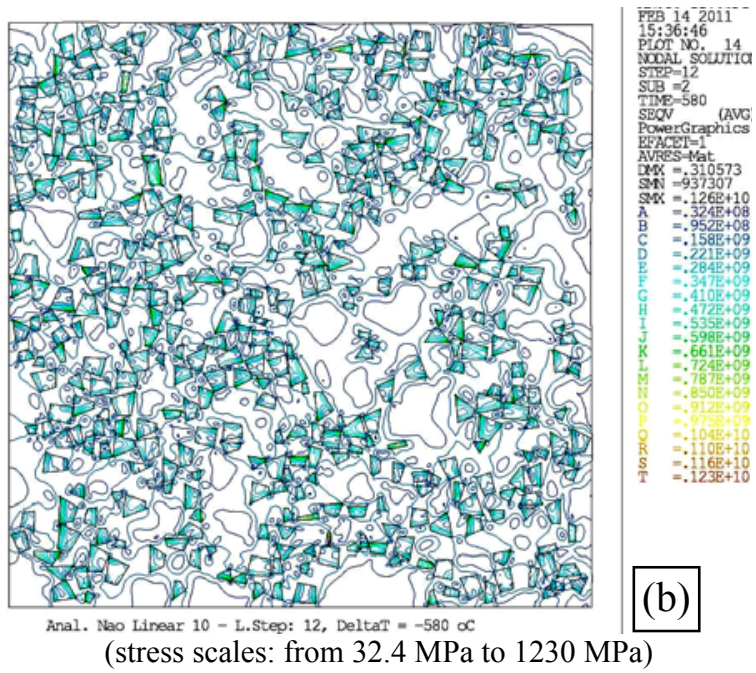

Figure 5. Typical results at $\Delta \mathrm{T}=-580^{\circ} \mathrm{C}$, models $40 \mathrm{~L}$.

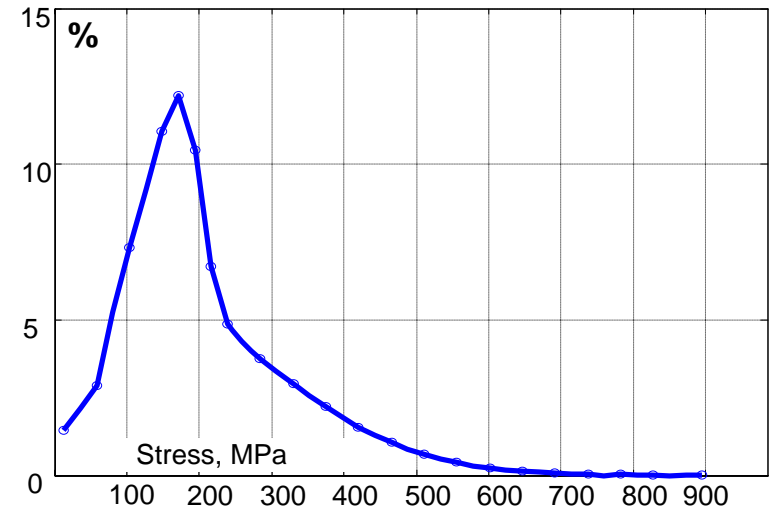

Figure 6. Typical iso-stress percentage distribution for one single analysis (model '20L'). 
Setting the number of iso-stress curves to 20 and considering that the maximum values of stress are too high (although less representative) implies a wide stress range associated to each curve/value of iso-stress.

Therefore, after this preliminary analysis of the results it was found appropriated to re-process the analyses generating new figures of iso-stress cutting the tail of the asymmetric percentages distribution.

Firstly, the maximum stress value was restrained to $650 \mathrm{MPa}$. This doesn't have any practical influence on the average stress and also in the mode stress values, since the accumulated percentage that is lost is less than $1 \%$. This is equivalent, roughly, to double the number of isostress curves.

Secondly, the cutting value was set to $330 \mathrm{MPa}$ which represents less than $5 \%$ of lost of accumulated percentage. This has a small influence on the average stress (not used in this work) and an even lesser influence on the mode stress. This means, again and roughly, that this procedure doubles the number of iso-stress curves.

\section{New Post-processing Result Analyses}

Figures $7 \mathrm{a}$ and $7 \mathrm{~b}$ present two typical stress distributions obtained with the $20 \mathrm{~L}$ size and $40 \mathrm{~L}$ size models, both when $\Delta \mathrm{T}=-580{ }^{\circ} \mathrm{C}$, obtained in the second phase of pos-processing when the maximum stress $\left(\sigma_{\max }\right)$ was limited to $650 \mathrm{MPa}$.

Figures $8 \mathrm{a}$ and $8 \mathrm{~b}$ present, also for $\Delta \mathrm{T}=-580$ ${ }^{\circ} \mathrm{C}$, two typical stress distributions (obtained with the 20L size and 40L size models), but limiting the maximum stress to $330 \mathrm{MPa}$.

\section{RESULTS ANALYSIS AND DISCUSSION}

To assess the influence of the model size on the most probable thermal stress value developed in the MMC composite $(\mathrm{Al}+\mathrm{SiC})$ due to its fabrication process, three sets of results with 20 models each one were compared. These sets have the size of $10 \mathrm{~L}$ (previous work), 20L and 40L (present work), where $\mathrm{L}$ is the average size of the particles.

One should remember that, in each doubled model (20L) there are, roughly, four times more particles than in a $10 \mathrm{~L}$ model, and in a $40 \mathrm{~L}$ model there are 16 times more particles than in a $10 \mathrm{~L}$ model (again, roughly speaking).

In each model of these sets, the thermal stress field that arises due to the MMC fabrication process was represented by 20 iso-stress curves equally spaced obtained when $\Delta \mathrm{T}=-580^{\circ} \mathrm{C}$. For each one of these curves its relative frequency, in percentage terms, was determined from an image analyzer algorithm developed in Matlab language. This algorithm was already presented and its results discussed elsewhere (Miranda, Libardi and Boari, 2009a)
The mode stress value was considered to be representative of the central tendency for the thermal stress estimate of a given model, and the 20 values in each set were statistically analyzed to get the mode average value and its standard deviation that represents the data dispersion in the set.
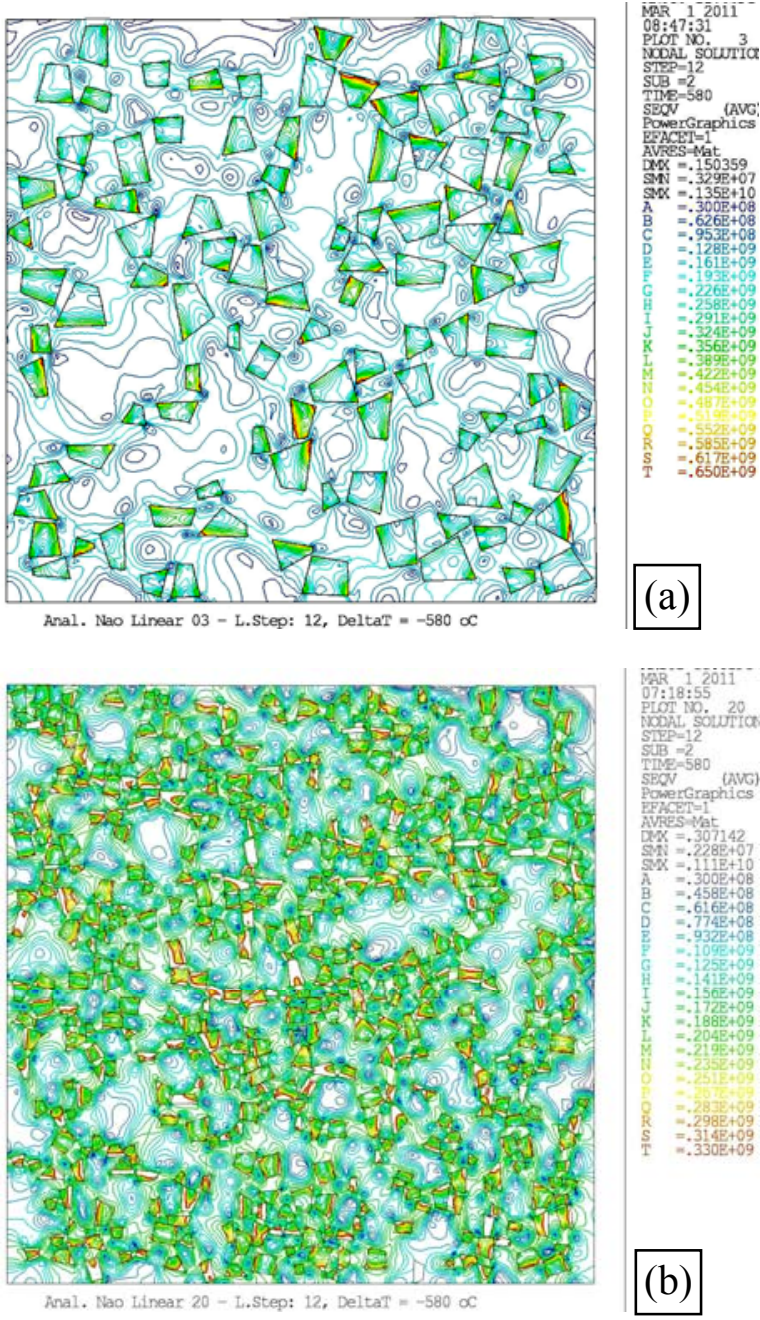

Figure 7. Typical results at $\Delta \mathrm{T}=-580{ }^{\circ} \mathrm{C}$ with $\sigma_{\max }=$ $650 \mathrm{MPa}$ (respect. from model 20L (A) and from model 40L (B)).

\section{Adopted Approaches to Analyze the Results}

No limitation on $\sigma_{\max }$. In the first approach to analyze the results, the raw values were adopted, i.e.: no limitation was imposed on the maximum stress value. It was observed a large dispersion in all of the three sets $(10 \mathrm{~L}, 20 \mathrm{~L}$ and $40 \mathrm{~L})$. It occurs due to the high level reached by the maximum stress values associated with the adopted fixed number of isostress curve (20 curves). However, this elevated stress level has very little significance for the central tendency value once they occur with very low frequency $(\sim 0 \%)$.

$\sigma_{\max }$ limited to $650 \mathrm{MPa}$. The second approach 
was adopted to restrain the maximum stress value to overcome this issue. Analyzing the distribution of the stress frequency in each model, the stress level of 650 $\mathrm{MPa}$ was chosen as the cutoff. This accounts for less than $1 \%$ of loss in the accumulated percentage, what is negligible in a practical sense and it is equivalent, roughly, to double the number of iso-stress curves.
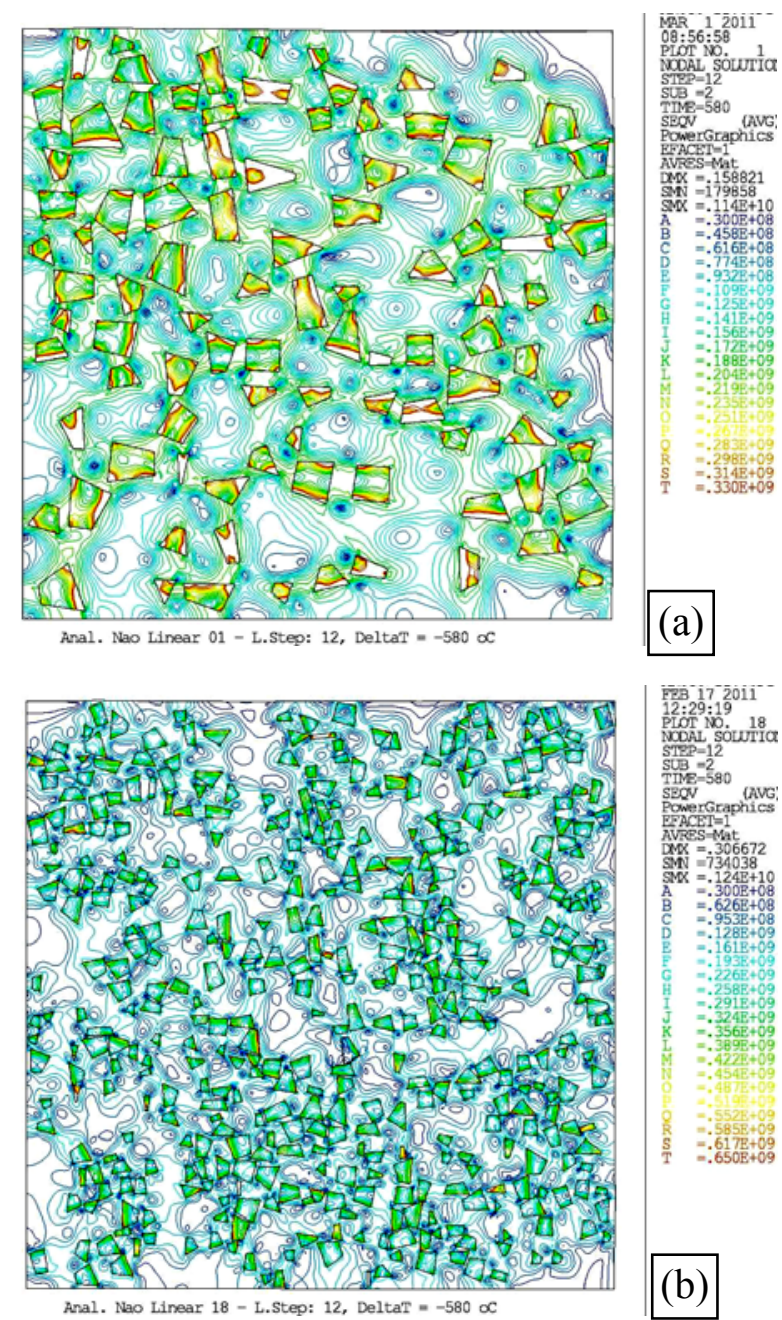

Figure 8. Typical results at $\Delta \mathrm{T}=-580{ }^{\circ} \mathrm{C}$ with $\sigma_{\max }=$ $330 \mathrm{MPa}$ (respect. from model 20L (A) and from model 40L (B)).

This approach was applied only to the $20 \mathrm{~L}$ and 40L models, developed specifically for the present work. For both sets it was found the value of 161 $\mathrm{MPa}$ as the most probable thermal stress value, with null dispersion.

$\sigma_{\text {max }}$ limited to $300 \mathrm{MPa}$. In a third approach for both sets (20L and 40L models), the stress level cutoff was reduced to $330 \mathrm{MPa}$, which represents a loss of accumulated percentage below $5 \%$ which is still negligible in a practical purpose and it is equivalent, roughly, to double again the number of iso-stress curves. The value of $172 \mathrm{MPa}$ was found as the most probable thermal stress value, still with null dispersion.

\section{Results Analysis}

Figure 9 summarizes the results obtained with these approaches while Table 2 shows the complete set of results obtained in the previous works as well as in the present work.

The refinement in the analyses results, as presented in this work, performing a cutting in the tail of the stress percentage distribution in each model, was not performed in the previous work (10L). So, a direct comparison is not possible.

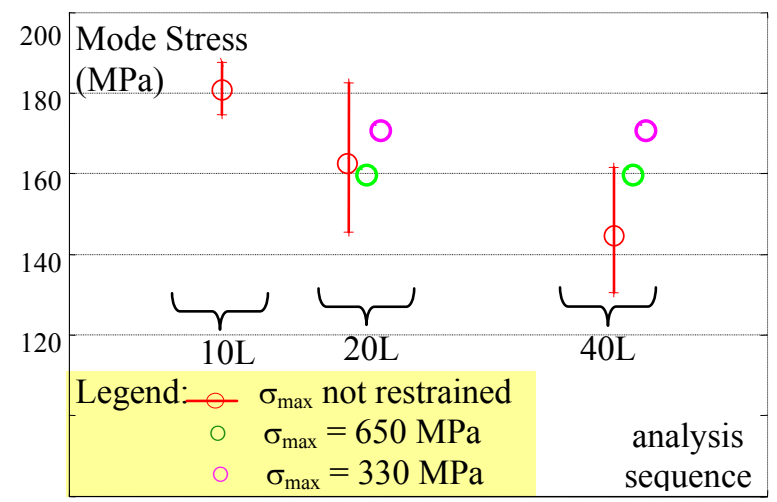

Figure 9. Summary of results from models 10L, 20L and $40 \mathrm{~L}$.

No practical difference was observed between the results in the $20 \mathrm{~L}$ and $40 \mathrm{~L}$ models when considering the stress cutting limit of $650 \mathrm{MPa}$ and when the cutting value was $330 \mathrm{MPa}$ (respectively, $161 \mathrm{MPa}$ and $172 \mathrm{MPa}$ for the estimated most probable thermal stress value in the composite). These values can be considered within the stress range established in the previous work considering a confidence interval of $95 \%$ (average value \pm 2 standard deviation).

So, considering only the present results, due to the lack of direct comparison with the previous work (10L), one can say that the model $20 \mathrm{~L}$ is a good approach to establish the most probable thermal stress value in an metal-matrix composite due to its fabrication process.

As the results have shown, due to their random size and shape some particles can experience strong stress gradients. This can lead them to brittle fracture. However, most of them are confined by the ductile surrounding material which makes more unlikely their fracture. Even so, the overall results remain once the stress redistribution will be very localized.

\section{ACKNOWLEDGEMENTS}

The authors are grateful to their institution, Nuclear and Energy Research Institute, IPEN$\mathrm{CNEN/SP}$, for the support given for this work. 
Table 2. Results Summary (including the Circular Linear and Non-Linear previous results).

\begin{tabular}{|c|c|c|c|c|c|}
\hline & $\begin{array}{l}\text { Model } \\
\text { Size }\end{array}$ & $\begin{array}{l}\text { Material behavior \& } \\
\text { Particle shape }\end{array}$ & $\begin{array}{c}\sigma_{\max } \\
(\mathrm{MPa})\end{array}$ & \multicolumn{2}{|c|}{$\begin{array}{l}\text { Most Probable Thermal Stress } \\
(\mathrm{MPa}) \text { and Std. Dev. (MPa) }\end{array}$} \\
\hline \multirow{3}{*}{$\begin{array}{l}y \\
\overline{0} \\
3 \\
3 \\
0 \\
0 \\
0 \\
0 \\
0 \\
0\end{array}$} & \multirow{3}{*}{$10 \mathrm{~L}$} & Linear/Circular & \multirow{3}{*}{ Not restrained } & $\sim 500$ & not calc. \\
\hline & & Non-Linear/Circular & & 150.0 & not calc. \\
\hline & & Non-Linear/Quadrilateral & & 180.8 & 6.5 \\
\hline \multirow{6}{*}{ 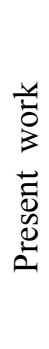 } & & \multirow{3}{*}{ Non-Linear/Quadrilateral } & Not restrained & 163.6 & 18.5 \\
\hline & 20L & & 650 & 161.0 & 0.0 \\
\hline & & & 330 & 172.0 & 0.0 \\
\hline & & \multirow{3}{*}{ Non-Linear/Quadrilateral } & Not restrained & 146.1 & 15.7 \\
\hline & $40 \mathrm{~L}$ & & 650 & 161.0 & 0.0 \\
\hline & & & 330 & 172.0 & 0.0 \\
\hline
\end{tabular}

\section{REFERENCES}

ANSYS v11.0, ANSYS Structural Analysis Guide \& Theory Reference Manual.

Beiser, A., 1963, Concepts of Modern Physics. $2^{\mathrm{a}}$ ed. Mc Graw-Hill Book Company, Inc., pp. 235246.

Boari, Z. M., 2000, Mathematical model - the influence of the particles distribution on the thermal stresses in a metallic matrix composite (in Portuguese - Modelo Matemático da Influência da Distribuição de Partículas de $\mathrm{SiC}$ nas Tensões Térmicas em Compósitos de Matriz Metálica), PhD Thesis, IPENUSP, São Paulo, Brazil.

Clyne, T. W., and Withers, P. J., 1993, An Introduction to Metal Matrix Composites. Cambridge University Press. First ed., pp. 44-64.

Humphreys F. J., Basu, A., and Djazeb, M.R., 1991, The Microstructure and Strength of Particulate Metal - Matrix Composites. In: Metal Matrix Composites - Processing, Microstructure and Properties, Publ: Riso National Laboratory, Materials Department, P.O. Box 49, DK - 4000 Roskilde Denmark; pp 51 - 66.

Kelly, A., and McMillan, N. H., 1986, Strong Solids. 3rd ed. Oxford Science Publications.

MATLAB version 7.6 (R2008a), Mathworks Inc., 2008.

Miranda, C. A. J., Libardi, R. M. P., and Boari, Z. M., 2009a, Thermal Stresses in an Al+SiC Composite due to the Fabrication Process. In: 20th International Congress of Mechanical Engineering, November 15-20, 2009, Gramado, Brazil.

Miranda, C. A. J., Libardi, R. M. P., and Boari, Z. M., 2009b, Particles Geometry Influence in the Thermal Stress Level in an SiC Reinforced Aluminum Matrix Composite Considering the Material Non-Linear Behavior. In: 2009 International Nuclear Atlantic Conference, September27 to October 2, 2009, ISBN: 978-85-99141-03-8, Rio de
Janeiro, Brazil.

Miranda, C. A. J., Libardi, R. M. P., and Boari, Z. M., 2009c, Non-Linear Thermal Stresses in an Aluminum Composite Reinforced with SiC Particles. In: $6^{\text {th }}$ International Congress of the Croatian Society of Mechanics, September 30 - October 2, 2009, Dubrovnik, Croatia.

Nardone, V. C., and Prewo, K. M., 1985, On The Strength of Discontinuous SiC - Reinforced Aluminum Composites - United Technologies Research Center - U.S.A - Scripta Metallurgica, Vol. 20, pp. $43-48$.

Withers, P. J., Stobbs, W. M., and Pedersen, O. B., 1989, The Application of the Eshelby Method of Internal Stress Determination to Short Fiber Metal Matrix Composites. Acta Metall., Vol. 37, No. 11, pp. 3061-3084.

\footnotetext{
Received: July 30, 201

Revised: August 30, 2011

Accepted: September 30, 2011
} 